
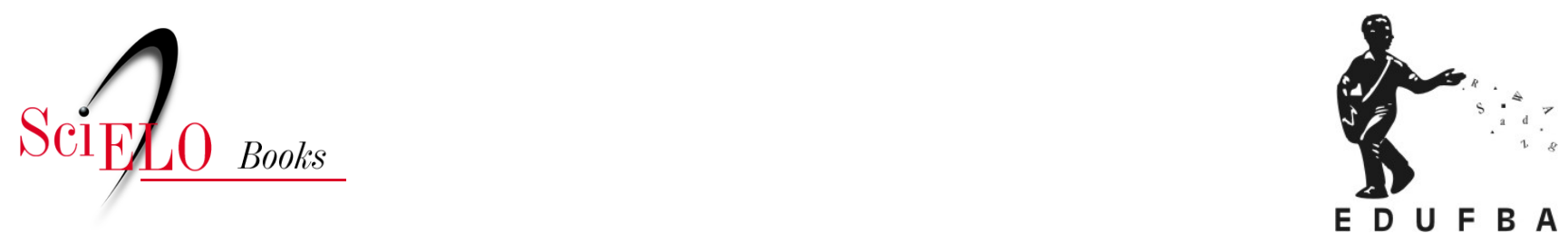

\title{
A criação de um cadastro único para uniformizar os critérios de concessão de benefícios sociais
}

\author{
José Carlos da Exaltação Torres
}

\section{SciELO Books / SciELO Livros / SciELO Libros}

TORRES, J.C.E. A criação de um cadastro único para uniformizar os critérios de concessão de benefícios sociais. In: Cadastro Único: tecnologia de reclassificação social [online]. Salvador: EDUFBA, 2016, pp. 115-123. ISBN: 978-65-5630-011-5. https://doi.org/10.7476/9786556300115.0009. \section{International license.}

All the contents of this work, except where otherwise noted, is licensed under a Creative Commons Attribution 4.0

Todo o conteúdo deste trabalho, exceto quando houver ressalva, é publicado sob a licença Creative Commons Atribição 4.0. 


\section{A CRIAÇÃO DE UM CADASTRO ÚNICO PARA UNIFORMIZAR OS CRITÉRIOS DE CONCESSÃO DE BENEFÍCIOS SOCIAIS}

Com base na análise da dinâmica e dos critérios de seleção de beneficiários dos programas focalizados de transferência de renda de abrangência nacional, especialmente o PETI, o Bolsa Escola e o Bolsa Alimentação, este capítulo descreve analiticamente o processo de criação de um cadastro comum a todos esses programas, fundamentado na atribuição de um NIS a cada pessoa nele inserida. No intuito de compreender como se definiu a base operacional desse novo cadastro, discutem-se os antecedentes desse mecanismo de identificação social, pautado no sistema utilizado pelo PIS dos trabalhadores brasileiros inseridos no mercado formal de trabalho, e a caracterização metodológica de um cadastro dessa natureza, bem como a forma como o cadastro está estruturado e os procedimentos estabelecidos para o seu funcionamento.

O Cadastro Único foi criado em 24 de julho de 2001 pelo então presidente da república Fernando Henrique Cardoso, através do Decreto n.․․ 3.877, em cuja ementa enunciava-se a instituição do Cadastro Único para Programas Sociais do Governo Federal. O Decreto determinava que, a partir de 15 de setembro daquele ano, esse Cadastro seria de uso obrigatório dos órgãos da administração pública federal, como condição imprescindível à "concessão de programas focalizados [...] de caráter permanente". (BRASIL, 2001e, Art. $1^{\circ}$ ) Excetuavam-se apenas os programas "administrados pelo Instituto Nacional de Seguridade Social, INSS, e pela Empresa de Processamento de Dados da Previdência Social, DATAPREV”. (BRASIL, 2001e, Art. 1ํㅜ) 
Esse decreto atribuiu aos órgãos gestores dos programas de transferência de renda a responsabilidade "pela articulação, abordagem e apoio técnico" aos municípios na operacionalização do Cadastro (BRASIL, 2001e, Art. $1^{\circ}$, $§ 3^{\circ}$ ) para a viabilização da logística de cadastramento.

Replicando o mecanismo adotado no programa Bolsa Escola, o processamento dos dados gerados para o Cadastro Único foi delegado à CEF. Uma das incumbências da Caixa era proceder, também aí, à “identificação dos beneficiários”, atribuindo-lhes um NIS. Esse número seria a chave de "unicidade" e "integração" do cadastro para "todos os programas de transferência de renda” (BRASIL, 2001e, Art. $2^{\circ}$ ), no intuito de imprimir racionalidade ao cadastramento realizado pelos órgãos em questão. Vale ressaltar que não aparece no Decreto n. ${ }^{\circ}$ 3.877/2001 referência ao PIS, o que não significa que não mais haja, uma vez que o Cadastro servirá também ao Bolsa Escola.

Em seu conjunto, esse Decreto não faz clara atribuição de competências, mas cria uma obrigação comum a "todos os órgão públicos federais" que operam transferência de renda focalizada, em sua ação junto aos municípios onde os programas são executados. Ademais, é apenas em relação à CEF que se apresentam atribuições definidas, corroborando normas anteriores, como a Lei n.ำ10.219/2001, que instituiu o Bolsa Escola, e na qual a Caixa é denominada "agente operador" do programa.

O Decreto n.. 3.877/2001 tem uma estrutura bastante enxuta, fato que se mostrará problemático quando da implantação do Cadastro Único. Em conta disso, em outubro de 2001, publicou-se um novo decreto, o qual acrescentará elementos ao anterior. Esse é um documento não numerado, identificado apenas como "Decreto de 24 de outubro de 2001". Em verdade, esse Decreto realiza quase que a regulamentação de um item específico daquele que instituiu o Cadastro: a forma de articulação dos órgãos federais em sua relação com os municípios, para fins de viabilização do processo de cadastramento. No novo documento, cria-se um "Grupo de Trabalho" para "articular, orientar e dar apoio técnico aos Municípios" na "sistemática de coleta de dados" do Cadastro Único, para que a mesma se desse de forma integrada. (BRASIL, 2001a, Art. $1^{\circ}$ )

Um dado importante é que o Decreto de 24 de outubro identifica quais são os órgãos que atuam nesse processo, os quais comporão o Grupo de Trabalho que está sendo criado: Casa Civil, Ministério da Saúde, MPAS, Ministério da Educação, Ministério do Desenvolvimento Agrário, SEAS e 
CEF. (BRASIL, 2001a, Art. $2^{\circ}$ ) Note-se que há algumas peculiaridades na composição desse grupo, uma delas é a presença da CEF, que não é um órgão da administração federal direta, o que pode, em princípio, ser justificado pelo fato de essa instituição ser responsável pelo processamento dos dados do Cadastro. Outra característica peculiar é a presença do Ministério do Desenvolvimento Agrário, o que sugere a existência de programas sociais específicos para a área rural. Mas o elemento que mais chama a atenção, do ponto de vista institucional, é a citação da SEAS. Isto porque ela é um órgão do MPAS, o qual já fora citado como partícipe do grupo. Junto a isso, o caput do Artigo $2^{\circ}$ designa à SEAS a coordenação do Grupo de Trabalho - mas indicando o Ministério ao qual a Secretaria está vinculada (MPAS) - e o Artigo $4^{\circ}$ altera o Decreto n. ${ }^{\circ}$ 3.877 para definir a alocação orçamentária da SEAS como fonte dos recursos para suprir as despesas com o processamento dos dados (o que significa pagar as despesas com a CEF). Essa extensão de poderes à Secretaria de Assistência corresponde ao status de ministério do qual gozava (Secretaria “de Estado”), mas pode estar apontando também para a tentativa de centralização da gestão dos cadastros dos programas sociais de transferência de renda, o que se daria nas dependências da Secretaria, mas que - como se verá mais adiante - não evitará dificuldades para a implantação do Cadastro Único.

\section{ENTENDENDO O NIS DO CADÚNICO}

O NIS foi adotado como chave de entrada dos registros individuais no Cadastro Único, sendo nele referenciadas todas as informações a respeito de cada pessoa cadastrada. Esse número, como se viu, foi instituído antes mesmo da criação do CadÚnico, através do Decreto n.․ 3.823/2001, que regulamentou o Programa Bolsa Escola, cuja implementação supunha um Cadastro Nacional de Beneficiários, no qual cada registro estaria associado a uma numeração padronizada. Para isso, a CEF, “agente operador” do programa, deveria cruzar os dados dos beneficiários com as bases do PIS, do PASEP e do CI, ${ }^{31}$ e a localização nesses registros seria utilizada como "código de identificação" dos beneficiários. Assim, o NIS foi criado como uma

31 Contribuinte Individual é uma modalidade de segurado da Previdência Social brasileira, criada pela Lei n. ${ }^{\circ} 9.876$, de 26 de novembro de 1999, que dá conta basicamente de formas de contribuição de pessoa física fora da relação de emprego. 
alternativa nos casos em que não houvesse registro e deveria ser "gerado de acordo com os conceitos e critérios básicos utilizados para o cadastramento no [...] PIS” ${ }^{32}$ (BRASIL, 20o1d, Art. 13, § 2º) Originariamente, portanto - do ponto de vista da codificação -, o NIS do Cadastro Único é um equivalente do cadastro do PIS.

O PIS foi criado pela Lei Complementar $n^{\circ} 7$, de o7 de setembro de 1970, com o objetivo de "promover a integração do empregado na vida e no desenvolvimento das empresas”. (BRASIL, 1970a, Art. 1ํ) A execução do programa se daria mediante a criação de um "Fundo de Participação", formado por recolhimento sobre o imposto de renda e sobre o faturamento das empresas em favor de seus empregados. A operação do Fundo foi delegada à CEF e, nessa condição, a Caixa ficou incumbida de organizar o "Cadastro-Geral dos participantes do Fundo" (BRASIL, 1970a, Art. $7^{\circ}$, $\S_{1}^{\circ}$ ), efetivado na abertura de uma conta individual para cada trabalhador, o que, por sua vez, condicionou-se ao fornecimento obrigatório de informações por parte das empresas. (BRASIL, 1970a, Art. $7^{\circ}$ ) À época, cada empregado tornou-se um cotista do Fundo de Participação, pelo que estava autorizado ao saque dos rendimentos gerados na operação dos recursos anualmente, conforme critérios estabelecidos na Lei (BRASIL, 1970a, Art. $8^{\circ}$ ), enquanto que os valores diretamente depositados seriam mantidos para a formação do "patrimônio do trabalhador” (BRASIL, 1970a, Art. 9º), facultando-lhe o saque integral em situações específicas, como casamento e aposentadoria, ou mesmo aquisição de casa própria. (BRASIL, 1970a, Art. $9^{\circ}$, $\S_{1^{\circ}}^{\circ}$; $2^{\circ}$ )

De forma semelhante, criou-se o PASEP, através da Lei Complementar n.o 8, de 3 de dezembro de 1970. Aí o agente operador será o Banco do Brasil, depositário dos recursos oriundos da administração pública em todos os seus níveis e responsável pela organização de um "cadastro geral de beneficiários”. (BRASIL, 1970b, Art. 5ํㅗ § 6) O mesmo mecanismo de saque dos rendimentos utilizado no PIS foi criado para o PASEP, bem como as condições para o saque integral. Posteriormente, mantida a distinção entre seus operadores, os dois fundos foram unificados, "sob a denominação de PIS-PASEP”, por força da Lei Complementar n.. 26 , de 11 de setembro de 1975, regulamentada pelo Decreto n. ${ }^{\circ}$ 78.276, de 17 de agosto de 1976 , cujo efeito remonta a $1^{\circ}$ de julho daquele ano. Alterou-se nesse momento o

32 Programa de Integração Social 
mecanismo de saque, exclusivamente para os trabalhadores cadastrados há mais de cinco anos e cuja renda mensal alcançasse no máximo cinco vezes o salário mínimo regional. Esses trabalhadores poderiam sacar até o valor de um salário mínimo, se houvesse fundos em suas contas para isso. (BRASIL, 1975, 1976) O Fundo PIS-PASEP passou a ser gerido por um Conselho Diretor designado pelo Ministério da Fazenda. (BRASIL, 1976, Art. 9º)

A Constituição Federal de 1988, em seu Artigo 239, modificou profundamente esse sistema, destinando os recursos do Fundo ao financiamento do seguro-desemprego - ali instituído como um "direito social dos trabalhadores rurais e urbanos" (BRASIL, 1988, Art. $7^{\circ}$, inciso II) - e ao pagamento de um abono anual, no valor de um salário mínimo, aos trabalhadores cujo rendimento mensal máximo alcançasse até dois salários mínimos. (BRASIL, 1988, 239, § $3^{\circ}$ ) As contas individuais e os seus critérios de saque foram mantidos para quem já as tivesse antes da promulgação da Constituição, não valendo mais, porém, a partir daquela data (5 de outubro de 1988) para os novos empregados. A partir das deliberações da Constituição, criouse o Fundo de Amparo ao Trabalhador (FAT), através da Lei n. ${ }^{7}$ 7.998, de 11 de janeiro de 1990, vinculado ao Ministério do Trabalho e constituído majoritariamente pelas contribuições do PIS e do PASEP. (BRASIL, 1990, Art. 10 - Art. 11) Essa mesma Lei dispõe sobre o Programa Seguro-Desemprego e sobre o Abono Salarial do PIS, financiados com recursos do FAT.

Atualmente, a gestão do Fundo PIS-PASEP orienta-se pelo Decreto $\mathrm{n} .{ }^{\circ}$ 4.751, de 17 de junho de 2003 . Nele, estão referendadas as principais disposições das leis originárias não modificadas por legislação posterior (BRASIL, 1970a, 1970b, 1975), a exemplo do seu Conselho Diretor (BRASIL, 2003b, Art. $7^{\circ}$ ) e do papel dos agentes operadores do PIS e do PASEP, a Caixa Econômica e o Banco do Brasil, respectivamente, adequando-os às disposições constitucionais, obviamente.

O que importa nesse quadro é identificar onde se vinculam o PIS e o NIS. Para isso, há que se observar que o PIS constitui-se num programa dotado de um cadastro específico dos seus participantes, os quais fazem jus a uma bonificação monetária periodicamente, seja através de contas bancárias individuais para os empregados anteriores à Constituição Federal de 1988, seja através de saque direto numa agência bancária, em cumprimento a um direito constitucional. Em qualquer dos casos, a referência principal é a relação de emprego, seguida da renda do trabalho. Por outro lado, o NIS representa um código de identificação individual, padronizado de acordo com 
os critérios utilizados para cadastrar os participantes do PIS, mas para servir como mecanismo de entrada para o registro de potenciais beneficiários de programas sociais de assistência, como o Bolsa Família, cuja referência principal é a renda familiar per capta, seguida de aspectos sociodemográficos das pessoas cadastradas. Analisados os públicos visados - no PIS, o trabalhador empregado; no NIS, a população de baixa renda - e os fins que os originaram - no PIS, a formação de um "patrimônio do trabalhador"; no NIS, a habilitação para benefícios socioassistenciais -, percebe-se que há entre o PIS e o NIS uma distinção conceitual e, simultaneamente, uma assimilação técnica.

\section{O QUE É O CADASTRO ÚNICO?}

O CadÚnico é a base de dados de que dispõe o governo federal, especificamente sobre a parcela da população brasileira considerada de "baixa renda", condição que a habilita ao processo de seleção de beneficiários para programas sociais de assistência, especialmente os de transferência de renda. Ramos e Santana (2002) consideram que, do ponto de vista metodológico, o CadÚnico constitui-se num instrumento indefinido entre um Registro Administrativo (RA) e uma "Pesquisa Domiciliar". Segundo esses autores, os RA são como "uma espécie de contabilidade que o Estado realiza de certo universo" (RAMOS; SANTANA, 2002, p. 12), servindo como parâmetro para implementação e avaliação de políticas públicas. Os RA estariam limitados por seu foco sobre o indivíduo, não alcançando, portanto, características socioeconômicas. As Pesquisas de Domicílio, por sua vez, têm “o objetivo específico de servir de base de dados para pesquisas, diagnósticos e formulação de políticas” (RAMOS; SANTANA, 2002, p. 13), oferecendo dados estatisticamente qualificados, mas dificilmente alcançando todas as características exigidas ao cumprimento de seus objetivos, requerendo que dados sobre programas sociais, por exemplo, sejam contemplados através de módulos suplementares, como acontece com a PNAD do IBGE. O Cadastro Único abriga tanto informações individualizadas quanto familiares e de condições de vida da população "pobre” do país, o que o deixa mais próximo de uma pesquisa domiciliar, mas não cumpre alguns requisitos para tal, como o critério do "rigor estatístico", observado quando a pesquisa é realizada por instituições que têm expertise nessa área, contemplando o desenho do questionário, a realização de testes prévios etc. (o que não se deu 
no Cadastro). (RAMOS; SANTANA, 2002, p. 15)33 Para Ramos e Santana, (2002) essa indefinição quanto ao tipo de instrumento que representa está na origem dos problemas que o CadÚnico enfrentou em sua implantação.

\section{ESTRUTURA E FUNCIONAMENTO DO CADASTRO}

Formalmente, o Cadastro Único é "constituído por sua base de dados, instrumentos, procedimentos e sistemas eletrônicos", como define o Decreto n.․ 6.135/2007, em vigor no período de realização desta pesquisa. (BRASIL, 2007a Art. $2^{\circ}$, $\$ 3^{\circ}$ ) O seu funcionamento requer a articulação de três atores principais: O governo federal, através do Ministério de Desenvolvimento Social e Combate à Fome-MDS, o governo municipal ou distrital e a CEF (definida esta como "agente operador" do Cadastro). O governo estadual, guardada a importância que pode desempenhar nos procedimentos de utilização e manutenção, não desempenha aí função direta, sua inserção se dá por conta do Programa Bolsa Família, como se verá mais à frente. $\mathrm{O}$ município pode ser considerado o principal ator nesse processo, pois é nele que se realiza a etapa operacional do cadastramento, com a coleta e digitalização dos dados, embora não defina as regras para isto.

O instrumento de coleta de dados é um pequeno módulo de formulários agrupados, denominado de "caderno azul", com campos para identificação do município, do domicílio, da família e de cada um de seus membros. Complementa-o um formulário específico para cadastramento de agricultor familiar. Para ter acesso aos formulários, o município precisa solicitá-los ao MDS, via internet, através do Sistema de Atendimento e Solicitação de Formulários (SASF). Há formulários avulsos disponíveis para impressão diretamente no site do Ministério, mas especificamente direcionado para complementação do formulário principal (caderno azul), atualização cadastral e cadastramento diferenciado - quilombolas, indígenas, população em situação de rua e abrigados. (BRASIL, 2008c, Art. 25)

O processo de cadastramento é composto de quatro fases distintas e complementares entre si: "I - identificação do público-alvo; II - coleta de dados; III - inclusão de dados no sistema de cadastramento; e IV - manu-

33 Essa análise sobre o Cadastro Único refere-se ao ano 2002, não considerando, portanto, as características incorporadas posteriormente. 
tenção de dados". (BRASIL, 2008c, Art. $3^{\circ}$ ) Em sua totalidade, essas tarefas estão concentradas na esfera municipal, e cada uma em si guarda determinados graus de complexidade. Não está aí inclusa a etapa de processamento dos dados, com atribuição de código padronizado de identificação para cada registro - o NIS, e sua efetiva inclusão na base de dados do Cadastro, tarefas de competência do agente operador, a CEF.

A identificação do público-alvo corresponde à localização das famílias cujo perfil de renda atende aos critérios do Cadastro Único, ou seja, famílias com renda mensal per capta de até meio salário mínimo. (BRASIL, 2007a) Recomenda-se aos municípios a utilização de dados do IBGE, DATASUS e INEP como subsídios ao mapeamento territorial das áreas onde se concentram essas famílias. (BARATTA et al., 2008)

Entre essa identificação e a coleta de dados, recomenda-se ainda a realização de treinamento de equipes de cadastradores. Embora essa atividade não figure no rol das obrigatoriedades, a complexidade do formulário utilizado nas entrevistas torna este treinamento indispensável. A coleta deve ser feita mediante visita domiciliar, o que serve de mecanismo de confirmação tanto da identificação prévia das famílias, quanto das informações declaradas por elas. Como alternativa a esta visita, podem-se utilizar postos de coleta, fixos ou itinerantes. Nesses casos, porém, uma amostra de $20 \%$ do total de cadastros registrados será submetida a averiguação mediante visita domiciliar. (BRASIL, 2008c, Art. 10)

A fase seguinte constitui-se da inclusão dos dados coletados no sistema eletrônico de cadastramento. Aí a tarefa articula o município e a CEF, responsável pela elaboração e distribuição dos softwares ou "aplicativos" necessários nesse processo. Em verdade, para que essa etapa se cumpra, realizam-se algumas subtarefas especializadas, exigindo ao menos a presença de um profissional com conhecimentos em informática capaz de compreender e realizar os procedimentos técnicos requeridos para esses aplicativos. A operação do cadastro é realizada em rede, entendida como a "integração de dois ou mais computadores para transferência de informações entre si”. Define-se um microcomputador como "servidor", onde se armazena a base de dados municipal e com o qual os computadores "clientes" estabelecem conexão para acesso à base. (CAIXA ECONÔMICA FEDERAL, [200-]) No caso de existência de uma única máquina, pode-se configurá-la como cliente e servidor simultaneamente. 
Os dados são digitados no "aplicativo de entrada e manutenção de dados", disponibilizado no web site da CEF para download livre. Os requisitos básicos para a instalação do aplicativo variam de acordo com a dimensão populacional do município e com o número de computadores disponíveis (um ou mais). Também as configurações de instalação estão relacionadas ao número de máquinas, bem como ao sistema operacional utilizado (Windows ou Linux). O software é desenvolvido em ambiente gráfico e reproduz os campos do formulário de coleta, o que permite certo grau de intuitividade na sua utilização, mas comporta um conjunto significativo de funcionalidades que requer uma operação bastante cuidadosa. Esse é um software utilizado em modo offline, de manipulação exclusiva do município, portanto, a digitação dos dados não corresponde à inserção imediata na base do Cadastro. Após a digitação, deve-se proceder à "extração" do arquivo de dados a ser enviado à Caixa Econômica. Esse envio requer a utilização de um outro aplicativo, o "conectividade social”, este de operação online, cuja finalidade principal é a troca de informações entre o servidor municipal e a central de processamento de dados da CEF.

Após o processamento - para o qual se define um prazo máximo de 48 horas -, a Caixa remete ao município um "arquivo-retorno", o qual deve ser acessado através do aplicativo principal ("entrada e manutenção de dados”) e adicionado à base de dados local. Nesse arquivo, o registro de cada indivíduo já está associado ao seu respectivo NIS, habilitando-o, portanto, à seleção para os programas sociais que utilizam o Cadastro, desde que dentro dos critérios estabelecidos pelos mesmos. Essa seleção se dá no âmbito do governo federal, o que é possibilitado pelo envio de uma cópia dos dados processados ao MDS pela CEF. Em verdade, o município coleta, digita e armazena os dados, mas não exerce qualquer ingerência no processo de seleção de beneficiários, no que tange aos programas de competência federal. Há ainda outros tipos de arquivo a que os municípios têm acesso, a exemplo do "arquivo-remessa", disponibilizado mensalmente, adicionando informações constantes da base nacional, e do "arquivo Base Caixa”, que contempla toda a base de dados municipal. Os arquivos "retorno" e "remessa" contemplam também a fase de manutenção de dados, que dá conta dos "procedimentos de alteração, atualização e revalidação" do cadastro. (BRASIL, 2008c, Art. 14) 